\title{
APROXIMACIÓN AL INTERÉS SUPERIOR DEL MENOR EN EL DERECHO INTERNAGIONAL PRIVADO ESPAÑOL*
}

\author{
APPROXIMATION TO SUPERIOR INTEREST MINOR IN PRIVATE \\ INTERNATIONAL LAW
}

\section{Ana FERnÁndez PÉREZ*}

RESUMEN: La reforma introducida por la Ley 8/2015 del 22 de julio, de modificación del sistema de protección a la infancia y a la adolescencia, intenta acotar el término "interés superior del menor". No obstante, no existe un concepto universal en materia de derecho internacional privado. Los derechos fundamentales de los menores se relacionan con este concepto para favorecer una intermediación entre el interés del menor y los valores propios del ordenamiento jurídico de cada foro, que requieren una serie de precisiones sobre su configuración.

Palabras clave: interés superior del menor, derechos humanos, derecho internacional privado, protección de menores.
ABSTRACT: The reform introduced by Law 8/2015 of Fuly 22, modifying the system of protection for children and adolescents attempts to limit the term of the best interest of the child. However, there is no universal concept of private international law. The fundamental rights of minors are related to this concept to favor an intermediation between the interest of the child and the values of the legal system of each forum that require a series of precisions about its configuration.

Keywords: superior interest minor, human rights, international private law, protection of minors.

* Artículo recibido el 2 de octubre de 2017 y aceptado para su publicación el 3 de noviembre de 2017.

** Profesora doctora de derecho internacional privado de la Facultad de Ciencias Jurídicas y Sociales de Toledo, Universidad Castilla La Mancha.

Boletín Mexicano de Derecho Comparado, nueva serie, año L, núm. 151, enero-abril de 2018, pp. 107-134. 
SUMARIO: I. Introducción. II. Protección de menores e interés superior del menor. III. El interés superior del menor en el derecho internacional privado de menores. IV. Manifestaciones del interés superior del menor en el derecho internacional privado. V. Conclusiones.

\section{INTRODUCGIÓN}

El ámbito de la protección de menores es uno de los sectores más influidos por los derechos fundamentales. Las obligaciones internacionalmente asumidas por los Estados referidas a los derechos humanos exigen "asegurar la coherencia del sistema jurídico a las situaciones jurídicamente heterogénea". ${ }^{1}$ La necesidad de respetar los derechos y libertades fundamentales, especialmente en el derecho de familia y en el ámbito de la protección de la persona, reclaman a los legisladores adaptar la normativa interna a estos derechos. Junto a ello, la influencia directa o indirecta de los derechos fundamentales en un ordenamiento jurídico interviene claramente en las normas de derecho internacional privado. ${ }^{2}$ Pero además, la normativa de DIPr relativa a los menores está construida sobre el principio del interés superior del menor, y sus normas deben interpretarse con arreglo a dicho principio. Este principio regulador de la normativa de los derechos del niño se funda en la dignidad misma del ser humano, en las características propias de los menores, y en la necesidad de propiciar el desarrollo de éstos, con pleno aprovechamiento de sus potenciales dentro de la naturaleza y alcance de la Convención de Derechos del Niño de 1989 (CDN). El desarrollo internacional de los derechos de los menores muestra una clara tendencia hacia la responsabilidad estatal en la protección y promoción de los derechos del menor. Esta evolución, en el marco de la protección del menor, se traduce en lo que se ha denominado "nueva dimensión de la función tutelar del Estado en materia de menores" o "estatalización de la condición del menor". ${ }^{3}$ Desde esta nueva concepción, la

1 Borrás Rodríguez, A., "La protección internacional del niño y del adulto como expresión de la materialización del derecho internacional privado: similitudes y contrastes", Pacis Artes. Obra homenaje al profesor fulio D. González Campos, t. II, Madrid, Eurolex, 2005, pp. 1286-1308.

2 Bucher, A., L'enfant en droit international privé, Ginebra, 2003, pp. 90-92.

3 Rosa G., Esteban de la, El acogimiento internacional de menores: régimen jurídico, Granada, Comares, 2000.

Esta obra está bajo una Licencia Creative Commons

Atribución-NoComercial-SinDerivar 4.0 Internacional, IIJ-UNAM.

Boletín Mexicano de Derecho Comparado, núm. 151, pp. 107-134. 
intervención del Estado no se limita únicamente a proteger al menor como objeto especial de protección en situaciones anómalas, sino que se compromete a realizar una política activa en su entera protección, adoptando las medidas necesarias para el desarrollo de su personalidad. El objetivo de este trabajo es la aproximación del concepto del interés superior del menor surgido tras la reforma operada por la Ley 8/2015, del 22 de julio, de modificación del sistema de protección a la infancia y a la adolescencia al derecho internacional privado de menores. Estudiaremos la relación entre el concepto de "interés superior del menor" con la protección de menores, para seguidamente abordar el papel que juega el interés superior del menor en el DIPr y la necesidad de una flexibilización del concepto para poder adaptar las situaciones privadointernacionales.

\section{PROTECGIÓN DE MENORES E INTERÉS SUPERIOR DEL MENOR}

\section{Planteamiento general}

La protección de los menores recogida en el principio 2 de la Declaración de los Derechos del Niño $(1959)^{4}$ determina que las leyes promulgadas con este fin deben tener como consideración fundamental el "interés superior del menor". Este principio se reitera y desarrolla en los artículos 3o. y 4 o. de la Convención sobre los Derechos del Niño de 1989 (CDN), ${ }^{5}$ que constituye actualmente el punto obligado de referencia en cuanto que su contenido recoge derechos que ya aparecían en textos más amplios, como los pactos internacionales de derechos humanos, pero que en la Convención se formulan de forma conjunta. Por lo tanto, el "interés superior del niño" es uno de los principios rectores de la GDN, cuyo concepto tiene muy

4 El principio 2 establece que "el niño gozará de una protección especial y dispondrá de oportunidades y servicios, dispensado todo ello por la ley y por otros medios, para que pueda desarrollarse física, mental, moral, espiritual y socialmente en forma saludable y normal, así como en condiciones de libertad y dignidad".

5 El artículo 4o. CDN dispone que "en todas las medidas concernientes a los niños que tomen las instituciones públicas o privadas de bienestar social, los tribunales, las autoridades administrativas o los órganos legislativos, una consideración primordial a que se atenderá será el interés superior del niño". Y para asegurar, en la mayor medida posible, la prevalencia del interés superior del menor, el preámbulo de la CDN establece que éste requiere "cuidados especiales". 
amplio alcance. A saber: el párrafo 1 del artículo 3o. de la Convención es un principio rector de importancia para la aplicación de la Convención en su conjunto.

Aunque este término siga siendo vago, dando lugar a su concreción en la interpretación por parte de los operadores jurídicos, su inclusión es un importante paso adelante en cualquier legislación nacional, ya que revela que en caso de conflicto entre los intereses del niño, por un lado, y los intereses y los deberes de los padres o del Estado o de la sociedad, por otro, prevalecerá el interés del menor. ${ }^{6}$ La Convención establece que todos los Estados tienen la obligación general de proporcionar la protección y el cuidado necesarios al niño (párrafo 2, artículo 3o.). Seguidamente, este instrumento recoge un auténtico catálogo o declaración de derechos fundamentales del menor: a la vida, a ser inscrito, a un nombre y a una nacionalidad, a mantener relaciones con ambos padres, a la libertad de expresión, conciencia y religión, y a la intimidad. ${ }^{7}$ Establece, además, la obligación de los Estados parte en orden a la protección del menor frente a los abusos físicos o mentales o cualquier tipo de explotación, y de asistencia en casos de desamparo o motivos de salud, junto a garantías de prestaciones sociales y alimenticias. Asimismo, contiene directrices generales sobre el valor supremo del interés del menor en los procedimientos de adopción y en los casos de secuestro internacional. Otros textos internacionales presentan asimismo una incidencia cierta en los derechos fundamentales de los menores. Así, el artículo 8o. del Convenio europeo para la protección de los derechos humanos y libertades fundamentales, del 4 de noviembre de 1950 (CEDH), al garantizar el respeto a la vida familiar, concreta el derecho de los menores a relacionarse con ambos padres, en una dirección similar a la que apunta el propio artículo 10.2 del Convenio de los Derechos del Niño de 1989. ${ }^{8}$

6 Buirette, P., "Réflexions sur la convention internationale des droits de l'enfant", Rev. belge dr. int, 1990, vol. 23, p. 62.

7 Rodríguez Mateos, P., "La protección jurídica del menor en la Convención sobre los Derechos del Niño de 20 de noviembre de 1989", Revista Española de Derecho Internacional, 1992, 2, pp. 465 y ss.; Durán Ayago, A., "Comentario a la Convención sobre los Derechos del Niño, hecha en Nueva York, el 20 de noviembre de 1989”, en Calvo Caravaca, A. L. y Carrascosa González, J. (dirs.), Legislación de derecho internacional privado. Comentada y con jurisprudencia, Madrid, Colex, 2002, pp. 687-705.

8 Moya Escudero, M., Aspectos internacionales del derecho de visita de los menores, Granada, Comares, 1998.

Esta obra está bajo una Licencia Creative Commons

Atribución-NoComercial-SinDerivar 4.0 Internacional, IIJ-UNAM.

Boletín Mexicano de Derecho Comparado, núm. 151, pp. 107-134. 


\section{La Carta de los Derechos Fundamentales de la Unión Europea} (CDFUE), ${ }^{9}$ por su parte, jurídicamente vinculante y con la misma fuerza que los tratados constitutivos de la UE, a partir de su entrada en vigor de 2009, recoge por primera vez en una norma de derecho originario y en un único texto, derechos sociales, civiles, políticos y económicos de los ciudadanos europeos y de todas las personas que viven en el territorio de la Unión. En este instrumento, los derechos de los menores también son objeto de protección, fundamentalmente en el artículo $24 .{ }^{10}$ Se regula el derecho a la protección y a los cuidados necesarios, el derecho a poder expresarse, a ser oído ${ }^{11}$ y a que su opinión sea tenida en cuenta, en relación con los asuntos que le afecten, en función de su edad y madurez. La influencia de la CDN (sobre todo del artículo 3o.) es evidente en el apartado segundo, en el que se regula el principio del interés del menor, ${ }^{12}$ y también en el párrafo 3, en el que se establece el derecho de los menores a mantener relaciones con ambos progenitores (aspecto muy relevante en los casos de divorcios, separaciones y sustracción de menores), salvo que dichos contactos sean contrarios al interés de los menores. Toma en consideración, como parte del establecimiento de un espacio de libertad,

9 DO C 364 de 18.12.2000. En junio de 1999, con el fin de destacar su importancia, el Consejo Europeo de Colonia consideró oportuno recoger en una Carta los derechos fundamentales vigentes en la Unión Europea (UE). La Carta debía contener los principios generales recogidos en el CEDH de 1950 y los derivados de las tradiciones constitucionales comunes de los países de la UE, así como los derechos económicos y sociales enunciados en la Carta social europea del Consejo y en la Carta comunitaria de los derechos sociales y fundamentales de los trabajadores, así como los principios que se derivan de la jurisprudencia del Tribunal de Justicia de la Unión Europea y la del TEDH.

10 El artículo 24 CDFUE dice: "1. Los menores tienen derecho a la protección y a los cuidados necesarios para su bienestar. Pueden expresar su opinión libremente. Ésta será tenida en cuenta en relación con los asuntos que les afecten, en función de su edad y de su madurez. 2. En todos los actos relativos a los menores llevados a cabo por las autoridades públicas o instituciones privadas, el interés superior del menor constituirá una consideración primordial. 3. Todo menor tiene derecho a mantener de forma periódica relaciones personales y contactos directos con su padre y con su madre, salvo si son contrarios a sus intereses".

$11 \mathrm{Al}$ hilo de este derecho, véase Otaegui Aizpúrua, I., "Derechos del niño. Artículo 24 Carta de los DD.FF.UE”, en J. I. Ugartemendia y S. García, J. Goizueta (dirs.), La Carta de los Derechos Fundamentales de la Unión Europea. Materiales de innovación docente, Cizur Menor, Thomson Reuters-Aranzadi, 2012, pp. 239-246.

12 Según consta en el Informe explicativo de la Carta, los redactores de la misma se basaron en el artículo 3o. CDN al redactar este apartado.

Esta obra está bajo una Licencia Creative Commons Atribución-NoComercial-SinDerivar 4.0 Internacional, IIJ-UNAM. Boletín Mexicano de Derecho Comparado, núm. 151, pp. 107-134. 
seguridad y justicia, la legislación de la UE en asuntos civiles con repercusiones transfronterizas, para la cual el artículo 81, TFUE, confiere competencias; esto incluye, entre otras cosas, "el derecho de visita que garantiza a los niños poder mantener de forma periódica contacto personal y directo con su padre y con su madre". La supremacía del interés del menor debe estar, por tanto, presente ante las autoridades públicas o instituciones privadas en cualquier situación en la que se encuentren los menores.

La Unión Europea expresó claramente su intención de aplicar y de promover los principios enunciados en el artículo 3o. de la CDN. ${ }^{13}$ Posteriormente, el artículo 3.5 del Tratado de Lisboa estableció que

...en sus relaciones con el resto del mundo, la Unión afirmará y promoverá sus valores e intereses y contribuirá a la protección de sus ciudadanos. Contribuirá a la paz, la seguridad, el desarrollo sostenible del planeta, la solidaridad y el respeto mutuo entre los pueblos, el comercio libre y justo, la erradicación de la pobreza y la protección de los derechos humanos, especialmente los derechos del niño, así como al estricto respeto y al desarrollo del Derecho internacional, en particular el respeto de los principios de la Carta de las Naciones Unidas. ${ }^{14}$

Los compromisos internacionales asumidos por la UE son vinculantes para sus instituciones y las autoridades de Estados miembros de la Unión Europea cuando apliquen el derecho comunitario. El principio del interés superior tal y como se proclama en la Carta de los Derechos Fundamentales de la Unión Europea y la Convención de las Naciones Unidas sobre los Derechos del Niño afecta a todas las políticas de la UE. Si bien es importante destacar el avance en el reconocimiento de los derechos de los niños y de las niñas, también hay que señalar que ni la CDN ni la CDFUE ofrecen una definición exhaustiva sobre el interés superior del menor. No obstante, en todas las acciones europeas que se adopten en relación con

13 Resolución del 8 de julio de 1992 del Parlamento europeo. Doc. A 3-0172/92, DO C, núm. 241, del 21/09/1992. La presente Carta no tiene carácter vinculante, ya que se trata de una propuesta que realiza el Parlamento Europeo a la Comisión para que ésta presente el proyecto de Carta comunitaria que se adjunta, con los principios mínimos y definiciones establecidos por el Parlamento.

14 El artículo 3o. fue redactado por el apartado 4) del artículo 1o. del Tratado de Lisboa por el que se modifican el Tratado de la Unión Europea y el Tratado constitutivo de la Comunidad Europea. Téngase en cuenta que el citado artículo fue renumerado por la tabla de correspondencias que figura anexa al Tratado de Lisboa.

Esta obra está bajo una Licencia Creative Commons

Atribución-NoComercial-SinDerivar 4.0 Internacional, IIJ-UNAM.

Boletín Mexicano de Derecho Comparado, núm. 151, pp. 107-134. 
los menores deberá tenerse siempre en cuenta, en primer lugar, el interés superior del menor y mostrar a los niños como titulares de derechos independientes, reconociendo al mismo tiempo la importancia de apoyar a las familias como principales encargadas de su cuidado. El interés superior del menor, en la legislación y en la jurisprudencia europeas, debe prevalecer sobre cualquier otra consideración en todos los actos adoptados en este ámbito, tanto por las autoridades públicas como por las instituciones privadas.

Por último, el Convenio sobre Derechos del Niño se complementa con el título I de la Constitución española, en particular con su artículo 39. La reglamentación española se ha adaptado a los principios específicos de este texto internacional a través de la Ley orgánica de protección del menor (LOPJM). Además de la declaración general contenida en el artículo 1o. de la LO 1/1996, del 15 de enero, el texto recoge una serie de derechos de los menores. De toda la normativa referente a menores se deduce un principio de orientación general: "el interés superior del niño", que, como veremos, es el valor de referencia de toda la reglamentación y obliga a todas las personas a garantizar la satisfacción integral y simultánea de los derechos humanos.

\section{La protección de menores en el derecho internacional privado}

La autonomía del derecho internacional privado de menores se asienta en las exigencias impuestas por el respeto a los derechos fundamentales de los menores, garantizados constitucional e internacionalmente, y el principio del "interés superior del menor" que los engloba. Es de destacar el papel que cumple la CDN, en la medida en que instaura los principios y derechos básicos que deben presidir la interpretación de las normas internas y convencionales. ${ }^{15}$ El régimen de derecho internacional privado

15 De conformidad con el Tribunal de Justicia, se desprende de las exigencias tanto de la aplicación uniforme del derecho comunitario como del principio de igualdad, que el tenor de una disposición de derecho comunitario que no contenga una remisión al derecho de los Estados miembros para determinar su sentido y su alcance normalmente debe ser objeto en toda la Comunidad europea de una interpretación autónoma y uniforme, que debe buscarse teniendo en cuenta el contexto de dicha disposición y el objetivo que la normativa de que se trate pretende alcanzar (vid. SSTJ, 18 de enero de 1984, Ekro, 327/82, ap. 11, y del 6 de marzo de 2008, Nordania Finans y BG Factoring, C-98/07, ap. 17). 
relativo a la protección de menores se encuentra, por tanto, condicionado por la vigencia en España de diversos textos convencionales multilaterales, que a su vez se encuentran condicionados por la normativa de derechos humanos. ${ }^{16}$ Además, esta materia se encuentra recogida en textos multilaterales específicos y en convenios bilaterales relativos a la protección de menores. ${ }^{17}$ La mayoría de estos acuerdos pueden "funcionar de manera complementaria, y su compatibilidad no genera más problemas que los que se extraen de su incorrecta aplicación por parte de nuestros tribunales". ${ }^{18}$

\section{Cuestión previa: la determinación de la minoría de edad}

Las normas de protección de menores de derecho internacional privado requieren para su aplicación una definición previa de qué se entiende por menor. La determinación de la mayoría de edad depende, en principio, de la aplicación de la legislación nacional. Por tanto, en los diferentes ordenamientos jurídicos, no siempre la edad determinante de la minoría es la misma. No obstante, junto con las legislaciones nacionales los convenios internacionales en la materia juegan un papel muy importante, y en ocasiones imponen una calificación autónoma del concepto de "menor", aplicable únicamente para el propio convenio.

Como regla general, el artículo lo., CDN, considera menores a los que aún no han cumplido los dieciocho años. En este mismo sentido se pronuncia el artículo 1o. de la LO 1/1996, del 15 de enero, de Protección del Menor, que limita su ámbito de aplicación a los menores de dieciocho años, a menos que la ley que les sea aplicable determine que han alcanzado anteriormente la mayoría de edad. La misma edad se recoge en el Convenio de La Haya en materia de adopción de 1965 (artículo 1.2) y en el artículo 3o. del Convenio de La Haya sobre protección del niño y cooperación en materia de adopción de 1993. En el artículo 12 del Convenio

16 Fernández Rozas, J. C. y Sánchez Lorenzo, S. A., Derecho internacional privado, 9a. ed., Madrid, Civitas, 2016.

17 Quizá el ejemplo más significativo sea el Convenio hispano-marroquí del 30 de mayo de 1997 sobre asistencia judicial, reconocimiento y ejecución de resoluciones judiciales en materia de derecho de custodia y derechos de visita y devolución de menores

18 Fernández Rozas, J. C. y Sánchez Lorenzo, S. A., Derecho internacional privado, 9a. ed., Madrid, Civitas, 2016.

Esta obra está bajo una Licencia Creative Commons

Atribución-NoComercial-SinDerivar 4.0 Internacional, IIJ-UNAM.

Boletín Mexicano de Derecho Comparado, núm. 151, pp. 107-134. 
de La Haya de 1961 sobre protección del menor se establece esta misma edad, pero considerando que es menor el que de forma acumulativa, según la ley de su nacionalidad y según la ley de su residencia habitual, se pueda considerar por tal. Si bien la traducción al español se convirtió en una disyuntiva, en el texto auténtico sigue apareciendo una acumulación de conexiones. ${ }^{19}$ El Convenio de La Haya, del 19 de octubre de 1996, sobre la competencia internacional, la ley aplicable, el reconocimiento y la cooperación internacional en materia de responsabilidad parental y de medidas de protección, se aplica "a los niños a partir de su nacimiento y hasta que hayan alcanzado la edad de 18 años" (artículo 2o.), edad que contempla asimismo el Convenio europeo de Estrasburgo, del 25 de enero de 1996, sobre el ejercicio de los derechos de los niños.

No obstante, no todos los convenios consideran los dieciocho años como la fecha límite de la minoría de edad. Así, en los convenios de La Haya de 1973 en materia de alimentos se establece la edad de veintiún años como justificación para negar el reconocimiento (artículo 26.1 del Convenio sobre reconocimiento) o para permitir reservarse el derecho de no aplicar el tratado (artículo 13.2 del Convenio sobre ley aplicable). En otros convenios, por el contrario, la edad es inferior. El Convenio europeo relativo al reconocimiento y la ejecución de decisiones en materia de custodia de menores, así como al restablecimiento de dicha custodia, hecho en Luxemburgo el 20 de mayo de 1980, considera menores a aquellos que tengan menos de dieciséis años, sin derecho a fijar su residencia según la ley de su nacionalidad, residencia habitual o según la ley del foro. El Convenio de La Haya del 25 de octubre de 1980 sobre los aspectos civiles de la sustracción internacional de menores fija la aplicación de sus normas en el límite de los dieciséis años (artículo 4o.). ${ }^{20}$ Finalmente, el Convenio hispano-marroquí, del 30 de mayo de 1997 sobre asistencia judicial, reconocimiento y ejecución de resoluciones judiciales en materia de derecho de custodia y derechos de visita y devolución de menores, circunscribe su aplicación a los menores de dieciséis años no emancipados.

19 Borrás Rodríguez, A., "El interés del menor como factor de progreso y unificación del derecho internacional privado", Revista furídica de Catalunya, núm. 4, 1994, pp. 915-967.

20 Pérez Vera, E., "Convenio no. XVIII de la Conferencia de La Haya sobre los aspectos civiles de la sustracción internacional de menores, de 25 de octubre de 1980 e informe explicativo del Convenio", suplemento del Boletín del Ministerio de Fusticia, núm. 1865, marzo de 2000. 
Por otro lado, el concepto de "menor" genera dificultades a la hora de determinar si se deben incluir o no a los menores emancipados dentro de esta noción. En algunas ocasiones, la exclusión de los menores emancipados se realiza en el propio convenio (como en el Convenio hispanomarroquí). En otras, se realiza una exclusión indirecta; por ejemplo, si el menor tiene capacidad para determinar su residencia (Convenio de Luxemburgo). En ambos casos la restricción se encuentra relacionada con la materia regulada en el propio convenio. No obstante, la emancipación, per se y con carácter general, no impide la necesidad de adoptar mecanismos de protección del menor, principalmente respecto de sus bienes. La inclusión de las medidas de protección de los menores emancipados en textos generales, como la LOPJM o el propio Convenio de La Haya de 1996, tal como sugiere su informe explicativo, ${ }^{21}$ así lo confirman. Además, no parece procedente diferenciar a los menores cuando las propias normas reguladoras no los distinguen. El principio interpretativo de "interés del menor" evidencia una interpretación extensiva del concepto.

\section{Contenido del concepto "interés superior del menor" y criterios para su interpretación}

Para dotar de contenido al concepto de "interés superior del menor", se modifica el artículo 2o. de la Ley Orgánica 1/1996, del 15 de enero, de Protección Jurídica del Menor, a través del artículo primero, número dos, de la LO 8/2015, del 22 de julio, de modificación del sistema de protección a la infancia y a la adolescencia ${ }^{22}$ - que desarrolla el mandato constitucional del artículo 39 de la Constitución para la protección social, económica y jurídica de la familia-, incorporando tanto la jurisprudencia del Tribunal Supremo de los últimos años como los criterios de la Observación general núm. 14, del 29 de mayo de 2013, del Comité de Naciones Unidas de Derechos del Niño, sobre el derecho del niño a que su interés superior sea una consideración primordial. Este concepto se define, entonces, desde una concepción triple.

\section{Idem.}

22 Lázaro González, I. E., "El interés superior del niño en la reforma del sistema de protección a la infancia y a la adolescencia", Familia y Sucesiones. Cuaderno Furídico, núm. 114, 2016, pp. 18-26.

Esta obra está bajo una Licencia Creative Commons

Atribución-NoComercial-SinDerivar 4.0 Internacional, IIJ-UNAM.

Boletín Mexicano de Derecho Comparado, núm. 151, pp. 107-134. 
i) Por una parte, es un derecho sustantivo en el sentido de que el menor tiene derecho a que cuando se adopte una medida que le concierna, sus mejores intereses hayan sido evaluados y, en el caso de que haya otros intereses en presencia, se hayan ponderado a la hora de llegar a una solución. Un derecho sustantivo, "no solo como un principio general de carácter interpretativo, a través de una fórmula en la que se especifican detalladamente los criterios que deben tenerse en cuenta para determinar su aplicación al caso concreto y los elementos que deben ponderarse a tales efectos". ${ }^{23}$

ii) Por otro lado, es un principio general de carácter interpretativo, de manera que si una disposición jurídica puede ser interpretada en más de una forma, se debe optar por la interpretación que mejor responda a los intereses del menor. En la adopción de medidas y decisiones que tengan por objeto a los menores concurren frecuentemente otros intereses legítimos (de los progenitores, familiares o de terceros), en cuyo caso el interés del niño como principio jurídico interpretativo determina que deberán priorizarse las medidas que respondan al interés del menor a la vez que respeten los otros intereses legítimos presentes, en la media de lo posible, y en caso contrario, debe primar el interés superior del menor sobre cualquier otro interés legítimo que pudiera concurrir (artículo 2.4 LOPJM), si bien valorando los derechos fundamentales de otras personas que pudieran verse afectadas.

iii) Pero además, en último lugar, este principio es una norma de procedimiento. Por tanto, las garantías procesales deben observar (artículo 2.5 LOPJM) los derechos del menor a ser informado, oído y escuchado, y a participar en el proceso de acuerdo con la normativa vigente. Esto se traduce en un "empoderamiento" del menor al reforzarse su derecho a ser oído y escuchado y participar en todos los procesos que le afecten de una manera "amigable", ${ }^{24}$ empoderamiento que también se concreta en el reconocimiento de sus debe-

23 Vaquero López, C., "Nuevas normas de derecho internacional privado estatal en materia de protección de adultos y de menores", Anuario Español de Derecho Internacional Privado, t. XVI, 2016, pp. 395-414.

24 Iglesia Monje, M. I. de la, "Ley Orgánica de modificación del sistema de protección a la infancia y adolescencia: las garantías de una protección uniforme a los menores más vulnerables en base a su supremo interés”, La Ley, núm. 8590, del 24 de julio de 2015. 
res como ciudadano, fundamentalmente el del respeto a los demás tanto en el ámbito familiar, escolar como social. Junto a esta garantía, es de destacar la necesidad de la intervención en el proceso de profesionales cualificados o expertos con formación suficiente para determinar las necesidades específicas de los niños; la participación de progenitores, tutores o representantes legales del menor o de un defensor judicial si hubiera conflicto o discrepancia con ellos, y del Ministerio Fiscal en el proceso en defensa de sus intereses. La adopción de una decisión que incluya en su motivación los criterios utilizados, los elementos aplicados al ponderar los criterios entre sí y con otros intereses presentes y futuros, y las garantías procesales respetadas. Finalmente, la existencia de recursos que permitan revisar la decisión adoptada que no haya considerado el interés superior del menor como primordial o en el caso en que el propio desarrollo del menor o cambios significativos en las circunstancias que motivaron dicha decisión hagan necesario revisarla. Los menores gozarán del derecho a la asistencia jurídica gratuita en los casos legalmente previstos.

En estas tres dimensiones, el interés superior del menor tiene una misma finalidad: asegurar el respeto completo y efectivo de todos los derechos del menor, así como su desarrollo integral.

El alcance real de la reforma de 2015 es limitado en el ámbito del derecho internacional privado español, "teniendo en cuenta que cada caso es diferente, por lo que será siempre el operador jurídico el que valore en función de las circunstancias lo que más conviene al menor y, en esta línea, los parámetros que ahora se han plasmado categóricamente en la Ley ya se venían aplicando". ${ }^{25}$ Puede que un desarrollo tan extenso de este concepto genere más dudas que cuestiones resuelva, pues por mucho que quiera concretarse, el interés superior del menor no ha dejado de ser un concepto jurídico indeterminado, ${ }^{26}$ "en la medida en que siempre debe quedar un margen de discrecionalidad al operador jurídico para concre-

25 Vaquero López, C., "Nuevas normas de derecho internacional privado estatal: una primera aproximación a las reformas legislativas julio 2015", Revista Aranzadi Doctrinal núm. 9/2015.

26 Durán Ayago, A., "El interés del menor en el conflicto de civilizaciones: elementos para su concreción en un contexto intercultural”, en Calvo Caravaca, A. L. y Castellanos 
tar en cada caso qué es lo que más conviene al menor". ${ }^{27}$ Desde el punto de vista del derecho internacional privado, este principio debe comportar soluciones flexibles y disposiciones materialmente orientadas, ${ }^{28}$ como veremos más abajo.

En este sentido, podemos decir que el interés superior del niño se concibe como el derecho a vivir, desarrollarse, crear su propia dignidad humana en el entorno familiar - siempre y cuando existan las condiciones suficientes- . No debemos olvidar que las circunstancias para que el niño viva en un entorno apto para su crecimiento no dependen sólo y exclusivamente de los padres, sino también del contexto social en que tendrá que emanciparse. Es por ello que el interés superior del niño, sin previamente reconocer derechos básicos como la educación, la vivienda, el acceso a un sistema sanitario (entre otros), se dimensiona y se vuelve un gran desafío. ${ }^{29}$

\section{EL INTERÉS SUPERIOR DEL MENOR EN EL DERECHO INTERNACIONAL PRIVADO DE MENORES}

\section{El "interés superior del menor" como derecho fundamental}

La CDN instituye la obligación de reforzar la prioridad del interés superior del menor asignándole una consideración primordial frente a otros intereses antagónicos. Salvaguardar el interés superior del niño no consiste

Ruiz, E. (eds.), El derecho de familia ante el siglo XXI: aspectos internacionales, Madrid, Colex, 2004, pp. 295-318.

27 Durán Ayago, A., "Aspectos internacionales de la reforma del sistema de protección de menores. Especial referencia a la adopción internacional", Anuario Español de Derecho Internacional Privado, t. XVI, 2016, pp. 415-462.

28 En el auto del Tribunal Constitucional 127/1986, del 12 de febrero de 1986, se proclama la "amplia discrecionalidad que caracteriza los procedimientos en materia de familia", teniendo en cuenta "como criterio básico y preferente el interés de los hijos". Asimismo, en la STC 143/1990, del 26 de septiembre, establece que "aunque la ley otorgue al juez muy amplias facultades para apreciar la conveniencia o no de acceder a la adopción solicitada, no puede aquél, en modo alguno, ignorar el mandato legal de dar audiencia a los padres del menor, pues sólo así podrá tener en cuenta todos los elementos de contraste necesarios, conducentes a una resolución acorde con los intereses prevalentes en la adopción".

29 Observación general 14, del 29 de mayo de 2013, del Comité de Naciones Unidas de Derechos del Niño, sobre el derecho del niño a que su interés superior sea una consideración primordial. 
únicamente en protegerlo de la victimización secundaria y situaciones difíciles mientras participa en el proceso de justicia como víctima o testigo, sino también en mejorar la capacidad del niño de contribuir a dicho proceso. Así pues, dar consideración primordial al interés superior del niño es compatible con amparar el interés de la justicia, y se ajusta a lo dispuesto en la Convención.

El interés del menor como fenómeno que engloba los derechos fundamentales se manifiesta de diferentes maneras en el derecho internacional privado, influyendo en el avance y en la unificación de esta disciplina. Este principio inspira no sólo la regulación material de las instituciones relativas a la protección del menor, sino también las reglas que articulan y constituyen el derecho internacional privado $;^{30}$ se ha ido introduciendo en el derecho internacional privado de menores y recorre e influye en todas las materias que puedan afectarlo, directa o indirectamente. Este concepto planea incluso sobre las técnicas específicas del conflictualismo clásico, y en especial sobre la calificación, la interpretación, integración, adaptación y sobre la excepción del orden público internacional. ${ }^{31} \mathrm{El}$ interés del menor opera, además, como mecanismo de control para la correcta aplicación de los instrumentos convencionales. Es decir, en los convenios internacionales el interés del menor se configura como una línea interpretativa a la luz de la cual la autoridad responsable ha de tomar la decisión más adecuada. ${ }^{32}$

El interés del menor es un concepto que desde el punto de vista del derecho internacional privado comporta la adopción de soluciones flexibles y disposiciones materialmente orientadas. ${ }^{33}$ Como acabamos de exponer, el principio del interés superior del niño parece haberse concretado en nuestro ordenamiento jurídico para las soluciones internas. No obstante, en el DIPr continúa apareciendo como un concepto jurídico indeter-

30 Durán Ayago, A., "El interés del menor en el conflicto de civilizaciones: elementos para su concreción en un contexto intercultural", en Calvo Caravaca, A. L. y Castellanos Ruiz, E. (eds.), El derecho de familia ante el siglo XXI: aspectos internacionales, Madrid, Colex, 2004, pp. 295-318.

31 Miguel Asensio, P. A. de, "Derechos humanos, diversidad cultural y derecho internacional privado", Revista de Derecho Privado, 1998, pp. 541-558.

32 Fernández Rozas, J. C. y Sánchez Lorenzo, S. A., Derecho internacional privado, 9a. ed., Madrid, Civitas, 2016.

33 Borrás Rodríguez, A., "El interés del menor como factor de progreso y unificación del Derecho internacional privado", Revista furídica de Catalunya, núm. 4, 1994, pp. 915-967.

Esta obra está bajo una Licencia Creative Commons

Atribución-NoComercial-SinDerivar 4.0 Internacional, IIJ-UNAM.

Boletín Mexicano de Derecho Comparado, núm. 151, pp. 107-134. 
minado, que necesita ser concretado en cada situación específica. ${ }^{34}$ Con la técnica del concepto jurídico indeterminado, la ley se refiere a una esfera de realidad cuyos límites no aparecen bien precisados en su enunciado; no obstante, pueden ser constreñidos en el momento de su aplicación. ${ }^{35}$ En otras palabras, la norma no nos ofrece la solución directa de cada caso, de tal modo que ésta debe ser hallada mediante criterios de valor o de experiencia, según la naturaleza del concepto. La inclusión de estas cláusulas en un ordenamiento jurídico puede tener ventajas e inconvenientes. Entre los aspectos positivos podemos mencionar la posibilidad de que el intérprete acomode las soluciones a criterios socialmente aceptados (artículo 3.1, CG), que han de prevalecer en cada momento en la aplicación de una materia tan cambiante como es el derecho de familia. En otras palabras, permite la adaptación del mandato legal a cada supuesto concreto, atendiendo a la diversidad de sujetos y circunstancias que puedan presentarse, así como el mantenimiento de su validez a lo largo de un amplio periodo a la posibilidad de ser interpretada de manera acorde con la evolución social y jurídica que se vaya produciendo. Entre los aspectos negativos que puede presentar una legislación que incluya este tipo de conceptos se encuentra, sin duda, la dificultad que plantea la interpretación personal, que puede acarrear desviaciones notables sobre aquello que la sociedad considera aceptable en un momento determinado. Así, por ejemplo, en un país desarrollado podría entenderse que

...el interés de los menores que viven en «países en vías de desarrollo», es trasladarse a vivir a España o al resto de países europeos, en donde encontrarían sus necesidades básicas cubiertas y disfrutarían de unos derechos sociales. Esto es sin duda un grave error. Esta interpretación parcial del concepto

34 González Martín, N. y Rodríguez Jiménez, S., El interés superior del menor en el marco de la adopción y el tráfico internacional. Contexto mexicano, México, UNAM, Instituto de Investigaciones Jurídicas, 2011.

35 E. Roca Trias llega a la conclusión de que la normativa de menores gira en torno al concepto jurídico indeterminado de interés superior del menor, que representa una evidente garantía de los derechos fundamentales. En Roca Trias, E., "El interés del menor como factor de progreso y unificación del derecho internacional privado, discurso de contestación a la académica de número doctora Alegría Borrás, en su discurso de ingreso en la Academia de Jurisprudencia y Legislación de Cataluña", Revista furídica de Catalunya, núm. 4, 1994. Véase también Roca Trias, E., "Familia y cambio social (de la casa a la persona)", Cuadernos Civitas, Barcelona, 1999. 
impediría aplicar la esencia del mismo, es decir, su derecho a ser oído, su derecho a permanecer con su familia, en su país de origen, además de conculcar la legislación vigente. ${ }^{36}$

En otros supuestos, como en caso de

....adopción internacional la falta de legalidad del proceso conlleva un supuesto de tráfico internacional de menores. Los padres adoptivos pueden pensar que el interés superior del menor es ofrecer lo mejor al niño en caso de irregularidades procedimentales. En ese momento el pretendido interés del menor se diluye o simplemente se vuelve inexistente. ${ }^{37}$

El interés del menor, en cuanto concepto jurídico indeterminado, se revela a priori como una noción intrínsecamente amplia, genérica, vaga, movediza e indefinible. En un segundo momento, sin embargo, es indispensable realizar un esfuerzo de concreción en cuanto a su contenido, que permita trasladarlo al DIPr en propuestas específicas. ${ }^{38}$ Como concepto jurídico indeterminado no debe olvidarse que existe siempre en el mismo un núcleo o zona de certeza en su concreción. Esta zona de certeza en la concreción del interés del menor viene dada en muchas ocasiones por los mismos datos legislativos o convencionales (en los supuestos de sustracción internacional de menores, el interés del menor es que no sea desplazado de su residencia habitual sin las garantías suficientes de estabilidad en la nueva situación, y su realización implica su retorno inmediato y la garantía del derecho de visita; en los supuestos en que se discute sobre las pensiones alimenticias respecto al menor, su interés es siempre la obtención efectiva de dichos alimentos, etcétera). Por tanto, para concretar el interés del menor hay que acudir siempre, en primer lugar, a los elementos de precisión que el derecho proporciona, cuantos más elementos de concreción facilite la norma, menor será el riesgo de atentado a la

36 Durán Ayago, A., "El interés del menor en el conflicto de civilizaciones: elementos para su concreción en un contexto intercultural", en Calvo Caravaca A. L. y Castellanos Ruiz, E. (eds.), El derecho de familia ante el siglo XXI: aspectos internacionales, Madrid, Colex, 2004, pp. 295-318.

37 Idem.

38 Navarro Atienza, M. A., "La legislación sobre la protección jurídica del menor y los conceptos jurídicos indeterminados”, Protección jurídica del menor, Granada, Comares, 1997, pp. 177-182.

Esta obra está bajo una Licencia Creative Commons

Atribución-NoComercial-SinDerivar 4.0 Internacional, IIJ-UNAM.

Boletín Mexicano de Derecho Comparado, núm. 151, pp. 107-134. 
seguridad jurídica que ha de presidir todo procedimiento..$^{39}$ No obstante, no puede desconocerse, por un lado, que estos elementos no siempre se encuentran positivizados de manera uniforme, y por otro, que en dicho proceso de concreción se entremezclan exigencias más allá de las estrictamente jurídicas, más cercanas a la sociología que al derecho. Nadie duda actualmente de la importancia de una aproximación sociológica en cualquier trabajo de investigación relativo al DIPr. ${ }^{40}$ Comprender los datos de la realidad social para analizar y explicar las respuestas que ofrece el DIPr a un determinado problema de tráfico jurídico externo se muestra especialmente relevante, en general, en el ámbito del derecho de familia y, en particular, en el estudio de la protección del menor. ${ }^{41}$ La concreción de cuál sea el interés del menor debe ser realizada en cada caso tanto por el legislador en el momento de regular una situación concreta que afecte a los menores como por las autoridades judiciales y administrativas que en cada caso concreto deban aplicar la norma de derecho interno o derecho convencional/institucional específico. Para determinar el interés superior del menor deberemos observar las necesidades concretas de cada caso y las circunstancias especiales que se puedan plantear. El interés del menor se ha relacionado tanto con el desenvolvimiento libre e integral de la personalidad del mismo y la supremacía de todo lo que le beneficie, más allá de las preferencias personales de sus padres, tutores, guardadores o administraciones públicas, en orden a su desarrollo físico, ético y cultural, como con su salud y su bienestar psíquico y su afectividad, junto a otros aspectos de tipo material, o relacionado simplemente con la protección de sus derechos fundamentales. ${ }^{42}$

Podemos concluir, en este punto, que el concepto de interés del menor en el derecho internacional privado constituye la proyección en los me-

39 Rubellin-Devichi, J., "Le principe de l'intéret de l'enfant dans la loi et la jurisprudence françaises", fCP éd. G. 1994, pp. 123 y 124.

40 Deprez, J., "Droit international privé et conflits de civilisations. Aspects méthodologiques", Recueil des Cours, t. 211, 1988-IV, pp. 11-341, esp. pp. 219-225.

41 Von Steiger, W. E., "La protection des mineurs en droit international privé", Recueil des Cours, t. 112, 1961-II, pp. 473-525, esp. pp. 473-474; Mayer, D., "Évolution du statut de la famille en droit international privé", Fourn. dr. int., 1977, pp. 447-469, esp. p. 477; en nuestra doctrina, Espinar Vicente, J. M., El matrimonio y las familias en el sistema español de derecho internacional privado, Madrid, Civitas, 1996, pp. 321-325.

42 STS 621/2015, del 27 de octubre, STS 15/2016, del 28 de octubre y STS 659/2016 del 10 noviembre de 2016, Rec. 2191/2015. 
nores de la protección de los derechos fundamentales en general. Esto es lo que ha pretendido regular la Ley Orgánica 8/2015, del 22 de julio, de modificación del sistema de protección a la infancia y a la adolescencia, al crear un nuevo marco de regulación de los derechos de los menores, en el que el "interés superior del menor" pasa a ser, en principio, un derecho fundamental y concreto. La ley fija una serie de

...criterios de resolución de conflictos para el caso de colisión del interés superior del menor con cualquier otro interés legítimo. Así, como criterio prioritario, se otorga prevalencia a las medidas que, respondiendo al interés del menor, respeten los otros intereses en juego; y subsidiariamente, en caso de no ser posible conjugar todos los interés en juego, se atribuye prioridad el interés superior del menor. ${ }^{43}$

El sistema español de protección de menores se encuentra especialmente afectado por la nueva configuración del principio de interés superior del menor, un principio que informa todas las disposiciones adoptadas en este ámbito por mandato de la normativa internacional sobre derechos fundamentales. ${ }^{44}$ No obstante, es comúnmente aceptado por la doctrina que, en tanto que principio informador de este sector de nuestro ordenamiento jurídico, la puesta en práctica del interés superior del menor no puede prescindir de cierta flexibilidad en su concreción, ${ }^{45}$ de manera que deberán ser los jueces quienes, atendiendo a las circunstancias del caso concreto, delimiten su alcance. ${ }^{46}$

43 López Azcona, A., "Luces y sombras del nuevo marco jurídico en materia de acogimiento y adopción de menores: a propósito de la Ley Orgánica 8/2015 y la Ley 26/2015 de modificación del sistema de protección a la infancia y adolescencia", Boletín de Información del Ministerio de fusticia, núm. 2185, enero 2016, pp. 1-89.; Lázaro González, I. E., "La reforma del Sistema de Protección a la Infancia y a la Adolescencia", TOP Familia y Sucesiones: Cuaderno furídico. Artículo Monográfico, ed. Jurídica SEPIN, junio de 2015, disponible en: http://goo.gl/Fyleo9.

44 Borrás Rodríguez, A., "El interés del menor como factor de progreso y unificación del derecho internacional privado", Revista furídica de Catalunya, núm. 4, 1994, pp. 915-967.

45 Fernández Rozas J. G. y Sánchez Lorenzo, S., Derecho internacional..., cit., p. 347; Durán Ayago, A., "La protección de menores en la era de la globalización: del conflicto de leyes a las técnicas de flexibilización", en Calvo Caravaca, A. L. y Blanco-Morales Limones, P., Globalización y derecho, Madrid, Colex, 2003, pp. 212-236, esp. 220.

46 Pérez Vera. E., "El derecho de protección de los menores", Comentarios a la Constitución socio-económica de España, Granada, Comares, 2002, p. 1309.

Esta obra está bajo una Licencia Creative Commons

Atribución-NoComercial-SinDerivar 4.0 Internacional, IIJ-UNAM.

Boletín Mexicano de Derecho Comparado, núm. 151, pp. 107-134. 


\section{El interés superior del menor como principio rector del derecho internacional privado español}

Los derechos fundamentales de los menores han experimentado una evolución significativa desde una etapa en la que predominó el poder paternal, hasta una etapa en la que prevalecen los derechos individuales. A este respecto, la evolución se refleja en los convenios de La Haya que, cronológicamente, abarcan 1902-1996, cuando la Conferencia de La Haya adoptó la Convención 19 de octubre de 1996 sobre competencia, reconocimiento, ejecución y cooperación en materia de responsabilidad parental y medidas de protección de los niños y los adolescentes. El estatus de "parte débil", y, por lo tanto, el interés de la referencia específica a su condición en el derecho internacional privado está presente en varias instituciones, como la patria potestad o, en su defecto, la tutela, la protección de las instituciones públicas, la filiación natural y adoptiva y, en caso de vulneración de estos mecanismos, como la sustracción de menores, en la adopción de medidas contra dichos ataques. Desde esta perspectiva basada en los derechos humanos,

...los requisitos de DIPr deben ser remodelados, cuando sea posible por interpretación, para salvaguardar los derechos fundamentales del niño, cuando se plantee un asunto en el que esté en juego la integración de un menor en su familia de adopción o en el seno de una familia que recurrió a la maternidad subrogada. El abandono del funcionamiento típico de las normas de DIPr, y la subsiguiente obligación positiva de resultado, revisten una importancia vital si los derechos fundamentales tienen que ser interpretados y aplicados de forma práctica y efectiva y no teorética o ilusoria —utilizando el lenguaje usado con asiduidad en la jurisprudencia del TEDH- Los requisitos del DIPr de familia clásico para el reconocimiento y ejecución de estados civiles foráneos no pueden constituir un obstáculo normativo para el reconocimiento de relaciones familiares y personales en el territorio del Estado requerido. ${ }^{47}$

El "interés superior del menor", hasta la reforma operada por la LO 8/2015, era considerado exclusivamente como un principio axiológico básico en la interpretación y aplicación de las normas de derecho

47 Baratta, R., "Derechos fundamentales y derecho internacional privado de familia", Anuario Español de Derecho Internacional Privado, t. XVI, 2016, pp. 103-126.

Esta obra está bajo una Licencia Creative Commons Atribución-NoComercial-SinDerivar 4.0 Internacional, IIJ-UNAM. Boletín Mexicano de Derecho Comparado, núm. 151, pp. 107-134. 
internacional privado español y del derecho material, encontrándose explícita o implícitamente en los textos internacionales y en el derecho interno. ${ }^{48}$ Como acabamos de exponer, este concepto jurídico indeterminado, que a raíz de la reforma de 2015 deja de serlo en parte, y pasa, de ser únicamente un principio, a ser concebido también como un derecho sustantivo y una norma de procedimiento. ${ }^{49}$ No obstante, como principio o guía que sigue siendo, su aplicación no puede prescindir de cierta flexibilidad en su concreción, ya que su indeterminación procede más de su carácter principal que de la indefinición del concepto, sin que exista una noción uniforme de derecho internacional privado que lo englobe. En palabras de Durán Ayago, "no hay que olvidar que el interés del menor sólo es alegable y concretable dentro de un determinado contexto normativo. O, lo que es lo mismo, el interés del menor sólo podrá hacerse valer respetando la legalidad vigente". ${ }^{50} \mathrm{El}$ "interés superior del menor" se erige entonces en un factor determinante dentro del derecho internacional privado, que llevará a la adopción de medidas de protección efectivas que positivicen este principio. El principio del interés superior del menor recogido en la CDN nos permite calificarlo como "norma positiva mínima" 51 aunque necesite reglas más detalladas con relación a la efectividad de los derechos que recoge, y por lo tanto

48 Fernández Rozas, J. C. y Sánchez Lorenzo, S. A., Derecho internacional privado, 9a. ed., Madrid, Civitas, 2016; Borrás Rodríguez, A., "La protección internacional del niño y del adulto como expresión de la materialización del derecho internacional privado: similitudes y contrastes", Pacis Artes. Obra Homenaje al profesor fulio D. González Campos, t. II, Madrid, Eurolex, 2005, pp. 1286-1308.

49 Durán Ayago, A., "Aspectos internacionales de la reforma del sistema de protección de menores. Especial referencia a la adopción internacional", Anuario Español de Derecho Internacional Privado, t. XVI, 2016, pp. 415-462.

50 Durán Ayago, A., "El interés del menor en el conflicto de civilizaciones: elementos para su concreción en un contexto intercultural", en Calvo Caravaca, A. L. y Castellanos Ruiz, E. (eds.), El derecho de familia ante el siglo XXI: aspectos internacionales, Madrid, Colex, 2004, pp. 295-318.

51 Rodríguez Mateos, P., "La protección jurídica del menor en la Convención sobre los derechos del niño de 20 de noviembre de 1989", Revista Española de Derecho Internacional, 1992, 2, pp. 465 y ss., destaca la limitación de los mecanismos de control que el Convenio fija, ya que únicamente se establece un Comité de Derechos del Niño encargado de examinar los informes que remitan los Estados sobre los progresos en la aplicación del Convenio. Dada la amplitud del número de Estados parte y su diversidad, los informes dados por los propios Estados no resultan la fuente más adecuada de información ni el mecanismo previsto el más efectivo.

Esta obra está bajo una Licencia Creative Commons

Atribución-NoComercial-SinDerivar 4.0 Internacional, IIJ-UNAM.

Boletín Mexicano de Derecho Comparado, núm. 151, pp. 107-134. 
un desarrollo más jurídico. ${ }^{52}$ Se considera, por tanto, como un principio general que abarca todos los derechos fundamentales, garantizando la protección efectiva de los menores, a fin de permitir el libre desarrollo de su personalidad. El interés del niño engloba todas las instituciones que, después, de alguna manera, pretenden responder a su protección efectiva, independientemente de la situación personal o familiar que se presente. ${ }^{53}$ Lo importante

...es que el nivel de protección de los derechos fundamentales se fundamente en valores comunes internacionales que se derivan de instrumentos internacionales. Como resultado, las jurisdicciones nacionales deben aceptar los fallos dictados en el extranjero y, en general, los valores jurídicos foráneos. Lo que da lugar a un concepto de orden público internacional con fuertes contornos transnacionales, porque se basa en la necesidad de hacerlo permeable por los valores basados en los derechos humanos tal y como se aceptan y comparten internacionalmente, y no tanto en la necesidad de preservar la coherencia interna del foro. ${ }^{54}$

El principio de interés superior del menor debe prevalecer y guiar las resoluciones de los órganos judiciales nacionales. El Poder Judicial debe valorar el interés superior del menor como un

...criterio primario para definir el lugar del niño en el DIPr de familia. Si rechazar el reconocimiento de una situación familiar debidamente constituida en el extranjero afecta desfavorablemente el interés superior del menor en un contexto determinado, un tribunal nacional, al aplicar su propio sistema de DIPr, debe mantener el estado civil legalmente establecido en el extranjero, respetando el derecho a la vida familiar tal y como se recoge en el artículo 8o. del GEDH. ${ }^{55}$

El exponente más importante en la aplicación de la normativa es sin duda el interés superior del menor, que limita y condiciona el ámbito de la competencia judicial internacional, el derecho aplicable, el reconoci-

52 Borrás Rodríguez, A., "El interés del menor como factor de progreso y unificación del derecho internacional privado", Revista Furídica de Catalunya, núm. 4, 1994, pp. 915-967.

53 Idem.

54 Baratta, R., "Derechos fundamentales y derecho internacional privado de familia", Anuario Español de Derecho Internacional Privado, t. XVI, 2016, pp. 103-126.

55 Idem. 
miento y ejecución de resoluciones y la cooperación de autoridades en la aplicación de las reglas específicas en la materia, y que trataremos en el siguiente epígrafe.

\section{MANIFESTAGIONES DEL INTERÉS SUPERIOR DEL MENOR EN EL DERECHO INTERNACIONAL PRIVADO}

\section{Competencia judicial internacional}

El interés superior del menor, en el sector de la competencia judicial internacional, surge al otorgar competencia a las autoridades más próximas al menor, que con carácter general serán las de su residencia habitual. Dentro de la normativa relativa a la protección de menores en el DIPr, podemos destacar el Convenio de La Haya, del 19 de octubre de 1996, relativo a la competencia, la ley aplicable, el reconocimiento, la ejecución y la cooperación en materia de responsabilidad parental y medidas de protección de los niños, en vigor en España desde el 1o. de enero de 2011, ${ }^{56}$ y que sustituye, entre los Estados parte, al Convenio de La Haya del 5 de octubre de 1961, sobre competencia de las autoridades y la ley aplicable en materia de protección de menores, y al Convenio de La Haya del 12 de junio de 1902, sobre la tutela de menores. Este convenio erige el principio del "interés superior del menor" como piedra angular de sus disposiciones. Por eso, la inclusión de cláusulas de flexibilización de la competencia, tales como las consagradas en los artículos. 8o. y 9o. Convenio de La Haya de 1996, facilitan y garantizan el hacer posible el interés del menor. ${ }^{57}$ Este convenio introduce cláusulas de flexibilización en la determinación de la competencia judicial internacional, como la del forum non conveniens y la del forum conveniens. ${ }^{58} \mathrm{El}$ artículo 15.1o. establece una regla de base caracterizada por la vinculación forum/ius y concretada en el postulado de aplicación a las medidas de protección del menor de la lex fori (artículo 15.10.), un postulado que responde a que la proximidad del interés descansa en normas de compe-

\footnotetext{
56 La ratificación estaba autorizada y propiciada por la Unión Europea a través de sus decisiones 2003/93/CE y 2008/431/CE.

57 Durán Ayago, A., "La protección de menores en la era de la globalización: del conflicto de leyes a las técnicas de flexibilización”, en Calvo Caravaca, A. L. y Blanco-Morales Limones, P., Globalización y derecho, Madrid, Colex, 2003, pp. 212-236.

58 Ibidem, p. 220.
}

Esta obra está bajo una Licencia Creative Commons

Atribución-NoComercial-SinDerivar 4.0 Internacional, IIJ-UNAM.

Boletín Mexicano de Derecho Comparado, núm. 151, pp. 107-134. 
tencia judicial internacional supeditadas a la residencia habitual del menor y a facilitar la labor de la autoridad que conoce del caso, ${ }^{59}$ que aplicará así la ley que conoce mejor. ${ }^{60}$ Sin embargo, precisada la conexión, el párrafo segundo de este precepto incorpora una cautela en forma de cláusula de excepción, según la cual "en la medida en que la protección de la persona o de los bienes del niño lo requiera, pueden excepcionalmente aplicar o tomar en consideración la ley de otro Estado con el que la situación tenga un vínculo estrecho". Como puede observarse, esta cláusula de excepción reposa no en el principio de proximidad, sino en el interés superior del niño. ${ }^{61}$

Por su parte, el Convenio de La Haya del 29 de mayo de 1993, relativo a la protección del niño y a la cooperación en materia de adopción internacional, contiene normas sobre la protección de menores en procedimientos de adopción internacional. En materia de sustracción de menores, el Convenio de La Haya del 25 de octubre de 1980 es el texto con un ámbito de aplicación mayor, debido a su vigencia en más de ochenta países, aplicándose a la cooperación judicial en materia de traslado y retención ilícito de menores, aunque no hace referencia a cuestiones de competencia, ley aplicable o reconocimiento. Aunque esta Convención está asentada en el interés del menor, éste, en cuanto tal, no está expresamente recogido en el texto, "debido a que el recurso por parte de las autoridades internas a una tal noción, implicaría el riesgo de traducir en él manifestaciones de particularismos social o cultural relevantes en una comunidad concreta, a fin de defender sus valores subjetivos respecto de otras comunidades". ${ }^{6}$ La parte dispositiva del Convenio no establece alusión explícita alguna al interés del menor, salvo como criterio corrector del objetivo convencional, que pretende asegurar el retorno inmediato del menor desplazado o re-

59 Fernández Pérez, A., "Funciones de las cláusulas de excepción en el proceso de localización de la norma en conflicto", Revista Española de Derecho Internacional, vol. 67, núm. 2, 2015, pp. 83-109.

60 Lagade, P., Informe explicativo, p. 43, disponible en: http://wrere.hcch.net/upload/expl34s.pdf.

$61 \quad$ Ibidem, p. 44. "El ejemplo más frecuentemente citado es el de la autorización pedida a las autoridades de la residencia habitual para vender un bien del menor situado en el extranjero. Es seguramente preferible que la autoridad a que se acude puede en tal caso aplicar la lex situs rei y conceder la autorización prevista por ésta, ley real, incluso si la ley de la autoridad a que se acude no exige en la materia autorización alguna. Podría también indicarse la aplicación de su ley nacional a la protección de niños extranjeros si resulta que estos niños van a volver en plazo breve a su país de origen".

62 Pérez Vera, E. "Convenio no. XVIII de la Conferencia de La Haya...”, cit., núm. 22. 
tenido ilícitamente. El Convenio entiende que en los casos de sustracción internacional de menores el interés superior del menor desplazado reside (salvo supuestos excepcionales) en "volver al lugar en que tenía su residencia habitual”. ${ }^{63}$ En el ámbito del Consejo de Europa, el Convenio europeo relativo al reconocimiento y la ejecución de decisiones en materia de custodia de menores, hecho en Luxemburgo el 20 de mayo de 1980, exige reconocer y acatar decisiones judiciales procedentes de más de treinta Estados partes. A pesar de ello, su alcance es limitado, ya que afecta sólo al reconocimiento de las decisiones sobre custodia y visita y la cooperación judicial en casos de secuestro de menores.

Fuera del marco convencional, el Reglamento (CE) núm. 1347/2000, del 29 de mayo de 2000, relativo a la competencia, el reconocimiento y la ejecución de resoluciones judiciales en materia matrimonial y de responsabilidad parental sobre los hijos comunes, denominado Reglamento "Bruselas II", reguló las situaciones de custodia de los menores resultantes de un procedimiento de crisis conyugal, que, aunque estuvo centrado en cuestiones de competencia y reconocimiento, también tuvo un impacto en los problemas de la ley aplicable. El Reglamento estuvo vigente desde el 1o. de marzo de 2001 hasta su sustitución por el Reglamento (CE) núm. 2201/2003 del Consejo, del 27 de noviembre de 2003, relativo a la competencia judicial, el reconocimiento y la ejecución de resoluciones judiciales en materia matrimonial y de responsabilidad parental (Bruselas II bis), cuyas disposiciones se aplican desde el 1o. de marzo de 2005.

El Reglamento (CE) número 2201/2003 del Consejo, del 27 de noviembre de 2003, relativo a la competencia, el reconocimiento y la ejecución de resoluciones judiciales en materia matrimonial y de responsabilidad parental, por el que se deroga el Reglamento (CE) núm. 1347/2000 (en adelante, "Reglamento Bruselas II bis"), ${ }^{64}$ establece que las normas de competencia están concebidas en función del interés superior del menor, y en particular en función del criterio de proximidad. El criterio de proximidad se corresponde con la residencia habitual del menor. ${ }^{65}$ Esto significa, por lo tanto, que los órganos jurisdiccionales del Estado miembro en

\section{Idem.}

64 Publicado en el DO L 338 del 23.12. 2003, y que sustituye al Reglamento núm. 1347/2000, publicado en el DO L 160 del 30.6.2000.

65 Lopes Pegna, O., "L'interesse superiore del minore nel regolamento no. 2201 / 2003", Rivista di diritto internationale, vol. 49, núm. 2, 2013, p. 364. 
el cual el menor tiene su residencia habitual son los órganos competentes por regla general, excepto en los casos de cambio de residencia del menor o mediante acuerdo entre los titulares de la responsabilidad parental. Asimismo, cabe la prórroga de la competencia judicial (artículo 12 del Reglamento), en determinados supuestos excepcionales y en determinadas condiciones ${ }^{66} \mathrm{a}$ fin de "atender al interés del menor", tal y como prevé el considerando décimo tercero. ${ }^{67}$

\section{Derecho aplicable}

En el ámbito convencional, la regla general será la aplicación de la ley de la autoridad que conociera del asunto, aunque también pueda aplicarse otra ley con la que el menor presente vínculos más estrechos. A falta de régimen convencional, será aplicable la ley del foro aunque exista la posibilidad de que otras leyes relacionadas con el supuesto puedan ser de aplicación. No obstante, debe protegerse el interés del menor, y el juez debe siempre encontrar la fórmula para salvaguardarlo dentro de los parámetros legales. El resultado material pretendido (interés del menor) puede obtenerse a través de técnicas diversas ${ }^{68}$ Entre ellas, la utilización de normas de conflicto clásicas con varios puntos de conexión, articulados de una forma determinada, para atender a la finalidad perseguida, o a través de puntos de conexión alternativos o puntos de conexión subsidiarios.

Cabría también optar por conexiones flexibles que permitan elegir, entre los distintos puntos de conexión que se ofrecen, la ley más apta para dar respuesta a una determinada necesidad del menor. Se trata de un proceso de materia-

66 Vara Parra, J. J., "El interés del menor en los foros de competencia judicial para las acciones de responsabilidad parental en el Reglamento (CE) núm. 2201/2003", Revista Española de Derecho Internacional, vol. LVIII (2006), 2.

67 Este considerando establece: “(13) Para atender al interés del menor, el presente Reglamento permite al órgano jurisdiccional competente, con carácter excepcional y en condiciones determinadas, remitir el asunto al órgano jurisdiccional de otro Estado miembro que esté mejor situado para conocer del asunto. Ahora bien, en este caso no se debe autorizar al órgano jurisdiccional al que se remitió el asunto a remitirlo a su vez a un tercer órgano jurisdiccional".

68 Borrás Rodríguez, A., "El interés del menor como factor de progreso y unificación del derecho internacional privado", Revista furídica de Catalunya, núm. 4, 1994, pp. 915-967, esp. 944-946. 
lización, que no asegura la justicia material, sino que se perfilan los intereses de política legislativa de los distintos ordenamientos jurídicos en presencia. ${ }^{69}$

El operador jurídico debe proceder a aplicar o no aplicar dichas normas y/o a modular su aplicación en un sentido o en otro, para dar satisfacción al "interés superior del menor". En efecto, a la hora de decidir estas cuestiones, el operador jurídico debe "monitorizar" el resultado de la aplicación de las normas de conflicto de modo que tal resultado encaje sin fisuras con el interés superior del menor. ${ }^{70}$ La norma de conflicto abandona, entonces, su generalidad y se vuelve más específica; renuncia a su rigidez y amplía el número de puntos de contacto a los que se puede recurrir para seleccionar el derecho material aplicable. La norma de conflicto debe presentarse bajo la apariencia de una regla graduada, que se adapta a la diversidad de las situaciones jurídicas. La justicia en derecho internacional privado debe armonizar la justicia material con la justicia conflictual. ${ }^{71}$

\section{Reconocimiento y ejecución de resoluciones extranjeras}

El interés del menor y su protección, en el sector del reconocimiento, sugieren evitar mecanismos formalistas que dificulten o impidan el reconocimiento y la ejecución de las sentencias extranjeras. Las fórmulas más factibles para combatir la rigidez que hace peligrar el aludido principio giran, en principio, en torno a los convenios internacionales. Por tanto, es necesario que entre los Estados se establezcan medidas que faciliten esta efectividad.

En tanto que los derechos fundamentales internacionalmente garantizados afecten los principios estructurales del $\mathrm{DIPr}^{72}$ el reconocimiento

69 Durán Ayago, A., "La protección de menores en la era de la globalización: del conflicto de leyes a las técnicas de flexibilización”, en Calvo Caravaca, A. L. y Blanco-Morales Limones, P., Globalización y derecho, Madrid, Colex, 2003, pp. 212-236.

70 Calvo Caravaca, A., "Gestación por sustitución y derecho internacional privado: consideraciones en torno a la Resolución de la Dirección General de los Registros y del Notariado de 18 de febrero de 2009", Cuadernos de Derecho Transnacional (octubre 2009), vol. 1, núm. 2, pp. 294-319.

71 Chabert, C., "L'intérét de l'enfant et les conflits de lois", Aix Marseille, 2001, pp. 17, 18,25 y ss.

72 Jayme, E., "Il diritto internazionale privato nel sistema comunitario e i suoi recenti sviluppi normativi nei rapporti con Stati terzi", Riv. dir. int. priv. proc., 2006, pp. 353 y ss., quien sigue el curso de este proceso, efectuando algunos comentarios críticos.

Esta obra está bajo una Licencia Creative Commons

Atribución-NoComercial-SinDerivar 4.0 Internacional, IIJ-UNAM.

Boletín Mexicano de Derecho Comparado, núm. 151, pp. 107-134. 
y ejecución de decisiones extranjeras debe ser estudiado sobre la base de principios comunes, con la finalidad de salvar contradicciones con la necesidad de tener un único estatuto familiar en los diferentes Estados. La idea de justicia en el DIPr puede ser ampliada si se entiende como un medio para alcanzar los derechos fundamentales de los individuos involucrados. En este sentido, para "materializar esta forma de intrusión del Derecho internacional en el DIPr de familia, la metodología para asegurar el reconocimiento de resoluciones judiciales foráneas y actos públicos en la jurisdicción del Estado requerido, se particulariza en instrumentos flexibles y apropiados, capaces de asegurar la continuidad de los estados civiles personales y familiar adquiridos más allá de las fronteras nacionales". ${ }^{73}$ En el ámbito del reconocimiento es donde "el principio de interés superior del menor cumple una función catalizadora del contenido del orden público". ${ }^{74}$

\section{CONCLUSiOnes}

A pesar de las distintas iniciativas que intentan acotar el término "interés superior del menor", no existe un concepto universal en materia de derecho internacional privado. En principio, existen tantas nociones como ordenamientos jurídicos y épocas en las que se desarrolle. Es ésta la principal razón por la que el derecho internacional privado español debe estar abierto a todas las acepciones que acoge el interés superior del menor en los ordenamientos jurídicos internos. Los derechos fundamentales de los menores se relacionan con este interés, para favorecer una intermediación entre esos conceptos universales con los valores propios del ordenamiento jurídico de cada foro. El interés del menor varía dependiendo del Estado en el que nos encontremos. La consagración universal de este criterio no impide las diferentes connotaciones que adquiere según los distintos contextos culturales. El concepto de interés superior del niño es flexible y adaptable. Debe ajustarse y definirse de forma individual, con arreglo a la situación concreta del menor afectado y teniendo en cuenta el contexto, la situación

73 Baratta R., "Derechos fundamentales y derecho internacional privado de familia", Anuario Español de Derecho Internacional Privado, t. XVI, 2016, pp. 103-126.

74 Vaquero López, C., "Nuevas normas de derecho internacional privado estatal en materia de protección de adultos y de menores", Anuario Español de Derecho Internacional Privado, t. XVI, 2016, pp. 395-414. 
y las necesidades personales. La flexibilidad del concepto de interés superior del niño permite su adaptación a la situación de cada menor. El interés superior del niño se erige en la consideración primordial a la hora de promulgar disposiciones legislativas y formular políticas en todos los niveles de los poderes públicos, así como al aplicar esas disposiciones legislativas y esas políticas.

En lo que respecta a las decisiones particulares, se debe evaluar y determinar el interés superior del niño según las circunstancias específicas de cada niño en concreto. Lo que sí es cierto es que se configura como un principio fundamental para elegir la mejor ley sustantiva y al mismo tiempo como criterio de interpretación de la normativa aplicable. Como principio, también permite la competencia judicial de la jurisdicción más próxima, o de cualquier autoridad ante situaciones de urgencia. En su faceta de derecho fundamental, el concepto permite una trasformación del orden público internacional de origen nacional en un orden público auténticamente internacional. Con ello sus soluciones se convierten en un núcleo de derecho sustantivo supranacional, vehículo para la defensa de los derechos fundamentales, y razón última del derecho internacional privado de menores. Como principio rector, permite otorgar flexibilidad al concepto y adoptar soluciones más acordes con cada situación. 